\title{
A Hermenêutica do Espaço: reflexões sobre a realidade geográfica de Eric Dardel ${ }^{1}$
}

\section{The Hermeneutics of Space: reflections on Eric Dardel's}

\section{Geographic Reality}

DOI: $10.12957 / \mathrm{ek} .2021 .59107$

\author{
Mariana Rodrigues da Costa Neves ${ }^{2}$ \\ Universidade Federal de Juiz de Fora \\ mariana.costaneves@gmail.com \\ https://orcid.org/0000-0002-9980-7335
}

\section{RESUMO}

Nenhuma outra reflexão revela-se tão fascinante quanto o conhecimento da realidade humana. E ressalte-se que as diferentes épocas e contextos históricos foram projetando, com insistência, sua imagem interpretativa do ser humano e, em consonância com ela, proclamaram os correspondentes códigos de conduta moral, principalmente os vinculados aos direcionamentos e postulados da Filosofia. E, de modo particular, a partir da Modernidade, o humanismo foi proposto como a condição de possibilidade do Conhecimento verdadeiro e como referência necessária para a vida e o fazer social. Nesse sentido, em 1952 foi publicada a obra O Homem e a Terra: Natureza da Realidade Geográfica, do geógrafo Eric Dardel, que foi traduzida para o português em 2011, a qual passou a versar sobre a realidade humana a partir da hermenêutica do espaço, refletindo

\footnotetext{
${ }^{1}$ Esse artigo possui resultados parciais da tese intitulada: A atitude fenomenológica e sua importância para a Geografia: desdobramentos atuais, diálogos metodológicos e concepções ontológica-hermenêutica da geograficidade das paisagens, defendida no ano de 2020, pelo programa de Pós-graduação em Geografia da Universidade Federal de Minas Gerais.

${ }^{2}$ Atua como Professora Substituta do Departamento de Turismo da Universidade Federal de Juiz de Fora (Deptur-UFJF). Doutoranda e Mestre em Geografia pelo Instituto de Geociências da Universidade Federal de Minas Gerais (Bolsista CAPES).
} 
sobre a realidade geográfica, numa perspectiva humanista. Esse trabalho surge, portanto, como resultado parcial de pesquisa de tese, desenvolvido entre os anos de 2016 e 2020 , com o escopo de apresentar a Hermenêutica do Espaço. Nesse sentido, apresentar-se-á a realidade (geográfica) dardeliana a partir de unidades de significações naturais/espaciais, utilizando como premissa a construção de arquétipos fundantes de Bachelard, e as construções de mundo material/imaterial, real/irreal. E a Hermenêutica do Espaço dardeliano será subdividida em Unidades de Significação denominadas Espaço Geométrico (material e telúrico), Espaço Aquático, Espaço Aéreo, Espaço Construído e Espaço Mítico.

Palavras-chave: Hermenêutica. Realidade Geográfica. Eric Dardel.

\begin{abstract}
No other reflection proves to be as fascinating as the knowledge of human reality. And it is noteworthy that the different epochs and historical contexts insistently projected their interpretative image of the human being and, in line with it, proclaimed the corresponding codes of moral conduct, mainly those linked to the directions and postulates of Philosophy. And, in particular, from Modernity, humanism was proposed as the condition for the possibility of true Knowledge and as a necessary reference for life and social activity. In this sense, in 1952 the work O Homem e a Terra: Nature of Geographic Reality, by geographer Eric Dardel, was published, which was translated into Portuguese in 2011, which started to deal with human reality from the hermeneutics of space, reflecting on the geographical reality, in a humanistic perspective. This work arises, therefore, as a partial result of a thesis research, developed between the years 2016 and 2020, with the scope of presenting the Hermeneutics of Space. In this sense, the Dardelian (geographical) reality will be presented based on units of natural / spatial meanings, using as a premise the construction of Bachelard's founding archetypes, and the constructions of a material / immaterial, real / unreal world. And the Hermeneutics of the Dardelian Space will be subdivided into Units of Meaning called Geometric Space (material and telluric), Aquatic Space, Aerial Space, Built Space and Mythical Space.
\end{abstract}

Keywords: Hermeneutics. Geographic Reality. Eric Dardel. 


\section{Introdução}

O conhecimento científico moderno ainda tem se pautado no axioma cartesiano: "Penso, logo conheço" (Cogito ergo sum). Esta proposição foi veiculada pelo filósofo, físico e matemático francês René Descartes em seu trabalho "Discurso sobre o método" e "Meditações metafísicas", no século XVII, que propunha como escopo estabelecer um método científico que não se baseasse nos sentidos, mas na racionalidade da existência. Ele propõe o método dedutivo como metodologia investigativa de uma pesquisa, que, partindo de observações minuciosas de um pesquisador, busca encontrar soluções através de seu raciocínio dedutivo. Essa metodologia de pesquisa, cartesiana, que perdura, há séculos, como uma construção técnico-científica, ratificada pelos modelos científicos difundidos na contemporaneidade, estabelece-se na ciência geográfica como um rigor científico, e ainda como forma de explicação e manutenção da vida do Homem (NEVES, 2020). A permanência e a reprodução desse tipo de metodologia ditam como única científica, tem corroborado para uma "desumanização da ciência geográfica", por se pautarem unicamente no racionalismo - que significa desconsiderar outros saberes, de não menor importância, que a ciência e a própria tradição filosófica têm encarado como uma outra vertente, vinculada somente à arte e às vivências cotidianas, e não passiveis de serem compreendidas como saber científico (CIDADE, 2001).

Nas ciências sociais, como também na Geografia (Ciências Humanas), a constituição da ciência moderna, no final do século XVIII ${ }^{3}$, se estabeleceu a partir de um discurso marcado por um objetivismo vinculado ao saber racionalista, consolidado no método científico cartesiano. Nesse sentido, a racionalidade geográfica também tem se pautaria nesta metodologia, que buscaria a explicação dos fatos do mundo a partir de uma lógica racional e instrumental (CIDADE, 2001; NEVES, 2020).

Contudo, na contemporaneidade, a epistemologia científica tem reavaliado seu posicionamento perante as concepções que tem por base essa vertente, e retomado a discussão de que nem tudo na ciência é determinado ou está cerceado pela dedução. Consideram-se, assim, que as artes, as religiões, as literaturas, as vivências, os saberes

\footnotetext{
${ }^{3}$ Cabe salientar que o corte epistemológico operado no "Iluminismo", no tempo renascentista, dividiu a Idade Média, (ciência antiga), que se pautava em similitudes, para o tempo Moderno, em que Deus é retirado da centralidade compreensiva da pesquisa para fazer advir uma ciência explicativa.
} 
comuns, ditos de "senso comum", o dia a dia, os ditos populares, as festas tradicionais, seriam ricos e vivos materiais que mostram uma abertura possível para se explicar e compreender o Homem, sua realidade e o real (NEVES, 2015).

Nesse sentido, um pesquisador geógrafo do século XX que pautou seus estudos nessa busca foi Eric Dardel. Ele desenvolveu sua principal teoria na obra O Homem e a Terra: Natureza da Realidade Geográfica, escrita em 1952, traduzida para o português em 2011, e foi muito esperada pelas escola humanista e cultural geográfica. É um pequeno livro, revestido de uma leitura poética naturalista descritiva, adentrada pelo confronto constante de teorias, por vezes paradoxais, no intuito de engendrar uma filosofia da realidade geográfica. Dardel é o autor da dualidade, e esse dualismo é pautado numa influência da filosofia clássica, com a Primitividade das Imagens, filosofia transcendental kantiana dos fenômenos empíricos e das coisas-em-si transcendentais, e a ontologia e hermenêutica de Heidegger, com os quais ele desenvolve vários pares dialéticos na tentativa de criar soluções para se "Ver e Habitar a Terra", para uma realidade além do real, a da realidade geográfica.

\section{Hermenêutica do Espaço}

Segundo Heidegger (2013), a hermenêutica tem como objetivo questionar e explicar a facticidade, ou seja, a situação característica da existência humana e apresentála como tarefa, tornando acessível ao ser-aí próprio em cada ocasionalidade, a fim de comunicá-lo e esclarecer uma alienação que pode ser compreendida como a diminuição da capacidade do indivíduo de pensar por si próprio enquanto ser-aí.

Ele ressalta, ainda, que a hermenêutica, não tem por objetivo a posse de conhecimentos, mas sim um conhecer existencial, isto é, um ser que surge da experiência de um "estar desperto", ou seja, dizer que está ativo em uma auto interpretação.

O ser é a essência, sendo o ente por sua vez tudo aquilo que existe, no entanto o ser-aí é o meio entre o ente e a essência. O Homem é o ser-aí, que em alemão chama-se Dasein, e possui capacidade e consciência de ter um ser, alcançando assim a autenticidade. De acordo com Besse:

A realidade geográfica não é inerte e indiferente, como um objeto diante de um sujeito. Ela é a realidade do Dasein, ou "realidade humana", uma vez que é 
com esta expressão que Dardel traduz, com base em Henry Corbin, o termo Dasein. Essa realidade me diz respeito, diz Dardel, ela traduz "minha inquietude, minha preocupação, meu interesse, meus projetos, meus laços" e da mesma maneira ela exprime o trabalho dos homens. Realidade da vida "sempre solidária com uma certa tonalidade afetiva", ela não significa, no entanto, a realização de uma geografia patética ou um romantismo da Terra. Ela deve ser entendida como um habitat, como circulação de coisas e de homens, como gênero de vida, ou seja, como meio da práxis humana. Porque no interior desta práxis que o homem, nos diz Dardel, "exterioriza sua relação fundamental com a Terra" (BESSE, 2014, p.91).

Dardel (2015), nesse sentido, questionará e explicará a realidade (geográfica) a partir de unidades de significações naturais/espaciais, utilizando como premissa a construção de arquétipos fundantes de Bachelard - água (1989), terra (1971), fogo (1994), ar (1990) -, e a construções de mundo material/imaterial, real/irreal. A Hermenêutica do Espaço dardeliano será subdividida em Unidades de Significação denominadas Espaço Geométrico (material e telúrico), Espaço Aquático, Espaço Aéreo, Espaço Construído e Espaço Mítico.

A primeira unidade de significação será o espaço geométrico (FIGURA 1), que para Dardel, representaria tudo o que se vê, e essas imagens (lugares e paisagens) seriam acessadas através da transcrição (verbal e escrita) e interpretação dos geógrafos.

Figura 1 - Espaço Geométrico Dardeliano

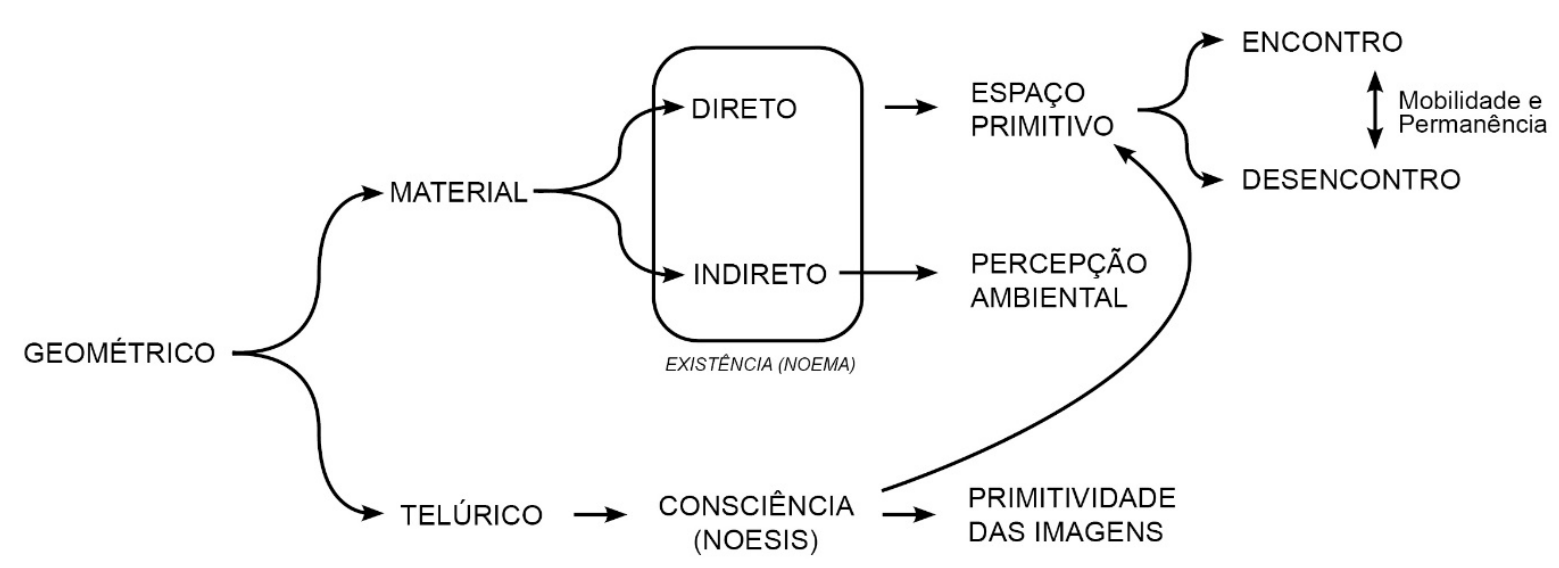

Fonte: NEVES, 2020. 
Essa interpretação do geógrafo será concebida por Dardel enquanto sujeito detentor da leitura dos espaços, ou seja, um leitor universal da linguagem do mundo. De acordo com o autor:

\begin{abstract}
Presença, presença insistente, quase inoportuna, sob o jogo alternado das sombras e da luz, a linguagem do geógrafo sem esforço transforma-se na do poeta. Linguagem direta, transparente, que "fala" sem dificuldades à imaginação, bem melhor, sem dúvida, que o discurso "objetivo" do erudito, porque ela transcreve o "texto" traçado sobre o solo (DARDEL, 2015, p.3).
\end{abstract}

Essas leituras do mundo conduzirão para a produção de imagens e a geografia dardeliana compreenderá essa interpretação de imagens como algo inato ao geógrafo, assim, a geografia proverá por si só a imaginação e a sensibilidade necessárias para compreender a realidade, e quem poderá transpor essa leitura desse texto será unicamente o geógrafo. É interessante notar que isso exclui todos os outros sujeitos de todos os processos, concedendo a faculdade da sensibilidade somente a um sujeito, o detentor do conhecimento científico. O que poderíamos inferir ser uma aproximação ao pensamento kantiano, no qual se observa uma primazia do sujeito sobre o objeto, e ao mesmo tempo do inato biológico kantiano:

\begin{abstract}
Se a geografia oferece à imaginação e à sensibilidade, até em seus voos mais livres, o socorro de suas vocações terrestres, carregada de valores terrestres, marinhos ou atmosféricos, também, sempre espontaneamente, a experiência geográfica, tão profunda e tão simples, convida o homem a dar a realidade geográfica um tipo de animação e de físionomia em que ele revê sua experiência humana, interior ou social (DARDEL, 2015, p.6).
\end{abstract}

Vale ressaltar, ainda, dois pontos relevantes aqui: o primeiro é que diferentemente de Sartre (2005), essas imagens percebidas não são explicadas enquanto fenômenos de aparição, ou série de aparições, nem mesmo das imagens enquanto Instante bachelardiano, em que elas seriam fluxo de imprevisíveis novidades a cada momento em que toma-se consciência de si (reflexão) no momento em que lança-se o olhar. Mas essas imagens se aproximam da teoria da percepção de Merleau-Ponty (1999) em que as imagens constituiriam um fluxo de percepções e imaginações a partir dos sentidos, porém de acordo com Dardel a ideia de compreensão e explicação se daria através de um sentido 
primeiro, que seria a visão, e que a interpretação dessas imagens (da Terra) seriam otimizadas pelo geógrafos. De acordo com ele:

A explicação se desloca discreta, sob o pitoresco das imagens, tanto mais surpreendente que, pela graça de estilo, o leitor compreende mais claramente esse texto. Dessa Interpretação feita por um geógrafo, temos acesso quase sem transição para o mundo do romancista em que a feição da Terra se anima com as vibrações coloridas do momento (DARDEL, 2015, p.3).

Nessa tentativa de abarcar a leitura da realidade e a explicação das imagens percebidas, Dardel propõe um dualismo entre mundo material e mundo imaginário, no qual o primeiro representaria todas as atividades humanas e o segundo a liberdade do espírito. Esse espírito estaria vinculado não ao espírito transcendental, mas as motivações e desejos de viajar, explorar e desbravar o mundo, que para Dardel, também seriam inatas aos geógrafos.

Vale ressaltar que esse dualismo representaria não somente a divisão entre as atividades diárias e cotidianas e as faculdades do desejo, como também se aproximaria fugazmente do ser diurno e noturno de Bachelard (JAPIASSU, 1976). Nesse sentido, não notamos uma transposição de teorias, mas uma aproximação, logo que Dardel não aprofundará sua análise, mas apenas confere ao mundo da imaginação o mundo do desejo, quase infantil, do desbravamento masculino, logo que o processo imaginante estaria recalcado no processo de conquista de lugares desconhecidos. Esse espaço geométrico será assim, subdividido em material e imaginário (telúrico) (FIGURA 1).

$\mathrm{O}$ espaço material será pertencente às atividades humanas e dividido em espacialização material direta e espacialização indireta. A primeira, material direta, será posicional, e refere-se ao ponto de vista do Homem; De acordo com Dardel:

Uma região montanhosa não é, antes de tudo, uma região que obstrui a circulação dos homens? A planície só é "vasta", a montanha só é "alta", a partir da escala humana, à medida de seus desígnios. (...), porém se a realidade só é geográfica para o homem, o que significa este "para"? Naturalmente, "para o homem" pode tomar frequentemente este valor claro de utensílio e significar "de interesse" ou "para o uso do" homem. Habitável, cultivável, navegável, essas aptidões não esgotam o sentido deste "para o homem", que exprimem simples e genericamente o ponto de vista do homem (DARDEL, 2015, p.8).

Já a espacialização indireta, ocorrerá através da influência física da Terra, ou seja, do clima, do relevo e do meio vegetal, sobre o homem. De acordo com Dardel: 
É importante não se acreditar no erro de que a espacialização geográfica se produz somente em virtude de um comportamento ativo. É o caso onde o homem é agenciado pelo ambiente geográfico: ele sofre influência do clima, do relevo, do meio vegetal. Ele é montanhês na montanha, nômade na estepe, terrestre ou marinho. A natureza geográfica o lança sobre si mesmo, da forma a seus hábitos, suas ideias, às vezes a seus aspectos somáticos (DARDEL, 2015, p. 9).

Nota-se, contudo, que a partir da espacialização direta e indireta que o Homem desenvolverá sua existência, que seria essência (Ser) e extensão. Dardel cria assim o Espaço Primitivo, no qual a existência se fixaria, e para onde todos os pensamentos, desejos e vontades se dirigiriam. Assim, Dardel cria um dualismo, dos encontros e desencontros.

\begin{abstract}
O Espaço Primitivo é onde se desenvolve a existência, porque ela é, em essência, extensão, porque ela procura um horizonte, direções, existências que dela se aproximam, porque a vida lhe oferece percursos a seguir, fáceis ou acidentados, seguros ou incertos. Ali onde os termos não podem mais se agarrar a uma realidade que resiste e que responde e não são mais do que cifras, é a geografia que, naturalmente, forneceu seu vocabulário porque ele é concreto e qualitativo, próximo e claro (DARDEL, 2015, p.13).
\end{abstract}

Nesse sentido, os encontros estariam vinculados a experiências concretas no qual o homem cria suas próprias rotas, suas estradas, seus caminhos, com direções determinadas. No sentido inverso, os desencontros estariam vinculados a uma estética dos caminhos que não foram planejados e projetados, colocando em evidência a experienciação, a imaginação, a poesia natural (DARDEL, 2015), e os sonhos da aventura de quem percorre aquele caminho.

É interessante notar que ao falar de caminhos percorridos, Dardel recorre ao tempo, e sobre a importância do encurtamento desse tempo e das distâncias na geografia:

Dirigir-se é também seguir em linha reta. Reto não significa sempre retilíneo. Porque na geografia, pelo menos, a linha reta não é em todos os casos “o caminho mais curto" de um lugar ao outro. Na montanha ou em terreno pantanoso, contornar os pendentes ou os lugares profundos permite chegar mais seguro e mais rapidamente ao ponto visado (DARDEL, 2015, p.12).

Ou seja, o que importaria para Dardel não seria a travessia enquanto reflexão, a pausa fenomenológica - até porque ele não se designa como fenomenólogo - mas a rapidez e encurtamento dos caminhos com que a geografia o permitiu encurtá-los. Ainda de acordo com o autor: 
Trilhas, vestígios de caravanas, estradas. Ansiedade do viajantes em uma região desconhecida onde a floresta, o planalto uniforme, a montanha fragmentada, privam a visão de qualquer ponto de referência. Em boa hora, o homem em sociedade fixou os traços que evitam essas hesitações e, ao mesmo tempo e na medida que a civilização impôs os transportes mais regulares e mais importantes, quis itinerários mais diretos, rotas retas, continentais e reais, ou então marítimas e fictícias. Essa mesma preocupação de dirigir-se, que lhe fazia anteriormente contratar guias, se mantém hoje em dia a partir dos inúmeros meios de indicação de rotas disponíveis. No entanto toda essa técnica empregada nas vias de comunicação representa apenas a relação geográfica original com a Terra mais aperfeiçoada e mais precisa, em que o espaço concreto é esse para o qual tem que se reportar, pelo qual deve passar ou no qual deve implantar as referências (DARDEL, 2015, p.12).

Ora, se a travessia não seria o momento de pausa para a reflexão, mas sim o momento da aventura, o que afinal estaria por vir nesses caminhos? E o que diferenciaria essas trilhas? Para Dardel essa referência estaria vinculada a liberdade situacional entre imobilidade e permanência. Ou seja, o que nos manteria entre os Encontros e os Desencontros seria a escolha de nos mantermos num sítio estável, ou num sítio inerte, e num movimento constante de lugares em lugares.

Já a unidade de significação do espaço geométrico telúrico é compreendida como experiência primitiva, não somente como relance visual perceptivo da Terra, mas implicando numa profundidade e ao mesmo tempo solidez da experiência concreta. E para adentrar nesse espaço telúrico, Dardel recorre a primitividade das imagens bachelardiana (BACHELARD, 1991). De acordo com Dardel:

\begin{abstract}
O arruinado, o maciço, o calcinado permanecem uma experiência concreta, até mesmo ingênua, em que a geografia se consubstancia e clama por uma espécie de geologia primitiva que é essencialmente um interesse, senão uma paixão pelos materiais e a estrutura da Terra, antes de se tornar uma ciência objetiva. Imagens que chegam primeiro como sensações táteis ou como manifestações visuais de uma intimidade substancial, antes de se decantar em ideias ou em emoções (DARDEL, 2015, p. 15).
\end{abstract}

A experiência telúrica se colocaria nesse sentido como um desejo inato sobre os componentes da Terra. Nesse sentido, Dardel recorre ao conceito de Consciência Imaginante sartriano (SARTRE, 1973) evocando a Terra para uma consciência imaginante, transcendendo-o, colocando-o a uma distância. Ou seja, a possibilidade de imaginar, implicaria numa irrealização que permitiria se presentificar uma pessoa, ou uma paisagem, ou um lugar, ou uma caminho, a título de sua ausência. Na sua intenção mesma, a consciência visaria o objeto, ainda que ausente, nadificando-o. A partir de um 
representante análogo, a consciência imaginante irrealiza um objeto, que transforma em imaginário. Esse processo valeria tanto para o produtor das imagens, o que imagina a paisagem ausente, quanto para o observador que recompõe as figuras como num quadro.

É interessante notar que a consciência dardeliana estaria no espaço geométrico telúrico (noesis) e a existência no espaço geométrico material (noema), recorremos então a Husserl, se só existe consciência enquanto consciência de algo, a consciência está a partir da primitividade das imagens para o espaço primitivo, delegando a Terra o papel central da existência e ao mesmo tempo da despertadora da consciência.

Após discorrer sobre o espaço material, Dardel adentrará mais profundamente sobre a primitividade das imagens (BACHELARD, 1991), apresentando o conceito de espaço aquático, espaço aéreo e espaço construído. O espaço aquático será compreendido enquanto lugaridade líquida, e na tentativa de explicar tal imagem, estado físico e processo de liquidez social, recorremos brevemente a Bauman (2001) e sua modernidade líquida.

Para melhor compreender a modernidade líquida, é preciso voltar ao período que a antecedeu, chamado por Bauman (2001) de modernidade sólida, que está associada aos conceitos de comunidade e laços de identificação entre as pessoas, que trazem a ideia de perenidade e a sensação de segurança. Na era sólida, os valores se transformavam em ritmo lento e previsível. Assim, tínhamos algumas certezas e a sensação de controle sobre o mundo - sobre a natureza, a tecnologia, a economia, por exemplo.

Já na modernidade líquida toda forma é temporária, tal como os líquidos, caracterizando-se numa incapacidade de manter uma forma estrutural:

Fluidez é a qualidade de líquidos e gases. Os líquidos diferentemente dos sólidos, não mantêm sua forma com facilidade. (...) Os fluidos se movem facilmente. Eles fluem, escorrem, esvaem-se, respingam, transbordam, vazam, inundam (...). Essas são as razões para considerar fluidez ou liquidez como metáforas adequadas quando queremos captar a natureza da presente frase na história da modernidade (BAUMAN, 2001, p. 8-9).

Assim, duas das características da modernidade líquida são a substituição da ideia de coletividade e de solidariedade pelo individualismo; e a transformação do cidadão em consumidor. Nesse contexto, as relações afetivas se dão por meio de laços momentâneos e volúveis e se tornam superficiais e pouco seguras (amor líquido). No lugar da vida em 
comunidade e do contato próximo e pessoal privilegiam-se as chamadas conexões, relações interpessoais que podem ser desfeitas com a mesma facilidade com que são estabelecidas, assim como mercadorias que podem ser adquiridas e descartadas.

Em Dardel também observamos esse movimento de análises de estruturas sociais que parte do mundo sólido (materialidade objetiva) para o mundo líquido(subjetivo). $\mathrm{O}$ mundo sólido é caracterizado já na rigidez das estruturas do espaço geométrico, iniciada pela própria designação, logo que na etimologia da palavra em grego antigo geo se refere à terra, e metria se refere à palavra métrica, ou seja, seriam propriedades de medidas da terra, do espaço. Em segundo, observamos a materialidade física da Terra, que é influência física, posicional e criadora de consciência.

Já no espaço aquático a perspectiva é de mobilidade e fluidez, mas sem perder os dualismo não relacionais. A ideia é que se flua como uma rio, no qual segue um caminho, possui uma imobilidade inata, diferente da imobilidade permanente, fixa de uma planície, mas sempre segue de um ponto ao outro.

O espaço aquático é um espaço líquido. Torrente, riacho ou rio, ele corre, ele coloca em movimento o espaço. O rio é uma substância que rasteja, que "serpenteia". As águas "deslizam através do frescor dos bosques espessos, docemente agitados; elas não murmuram, elas correm penosamente". No funcho dos rios límpidos, o jogo móvel das luzes e das sombras azuis, esse reino secreto "cheio de flores imóveis e estranhas" provê uma experiência direta da espacialidade aquática. A água corrente, porque é movimento e vida, aplaina o espaço (DARDEL, 2015, p.20).

É interessante notar que a liquidez também está na voz. É ela que representa o arquétipo do discurso, que sai do mundo geométrico, duro, árduo e seco da terra, para o da possibilidade, vasto, que corre diversificados lugares, que sai da nascente e direciona para o mar.

Por sua mobilidade, pelo salto soletrado da corrente ou pelo movimento ritmado das vagas, as águas exercem sobre o homem uma atração que chega à fascinação. Há uma palavra que encanta, uma substância que atrai. Palavra discreta ou turbulenta, acariciante ou ameaçadora, que dá ao rio ou ao mar uma personalidade. "A terra é muda", e o oceano é uma voz. (...) Ele fala à terra, fala à costa, dialoga com seus ecos. É o esforço que faz o mundo para falar (DARDEL, 2015, p.22).

Já o espaço aéreo, diferente do espaço líquido, é considerado permanente, daquilo que se sobrepõe a tudo e não se altera com o tempo, límpido, tornando-se a expansão e plenitude do Ser, invisível, logo que não se recorre a um único sentido da visão, mas isso 
não quer dizer que o fenômeno não ocorra; e imperceptível, ou seja, que não depende dos sentidos para existir, o que não o impede de dar a sensação imediata da sua presença (DARDEL, 2015).

Vale ressaltar que esse espaço aéreo é também dual, e tal como Bachelard (1977), dividido entre diurno e noturno.

O espaço diurno separa as coisas e as deixam prontas para a atividade. Ele dá
aos objetos seus "corpos", ao homem o sentido de suas tarefas. Somos já
inteligência desde que amanhece o dia, a nossa atenção é o apelo que ele nos
lança para realizar nosso vir a ser. Mas nós também estamos de acordo com a
noite, com seu poder de irrealizar o mundo, de aprofundá-lo em volume e
silêncio. A noite têm "um conteúdo positivo próprio": o mundo noturno
dissolve os limites e as distâncias, aumenta a montanha e preenche a planície.
Ela é repouso, paz do entardecer, porém também mistério e devaneio. Sombra
e luz, o espaço aéreo se encerra no feérico, no mágico (DARDEL, 2015, p.24).

O que diferencia primordialmente Bachelard de Dardel nesse dualismo é que Bachelard trata Diurno e Noturno enquanto estrutura do Ser para a psicanálise do conhecimento científico. Assim Bachelard propõe dois caminhos distintos de análise, o da Razão Diurno, e o do Devaneio Noturno, implicando um Ser Dual Dialético. Já para Dardel, não existe psicanálise do conhecimento, nem dialética, e a Estrutura do Ser estaria no Espaço Geométrico, o diurno, nesse sentido, representaria as possibilidades realizáveis do homem, e o noturno as possibilidades tangenciáveis das distâncias imagináveis entre o homem e os lugares.

Já o espaço construído, de acordo com Dardel (2015), é a obra do homem, sua morada, seu espaço vivido, onde se encontram seus lugares de vivência, sua história, onde é o palco da sua socialização, onde encontram-se os símbolos que particularizam sua realidade e sua relação com o Outro.

(...) a forma mais importante do espaço construído está ligada ao hábitat do
homem (...) a grande cidade moderna onde o homem é moldado na sua
conduta, nos seus hábitos, nos seus costumes, suas ideias e seus sentimentos,
por esse horizonte artificial que o viu nascer, crescer, escolher sua profissão.
Entre a vila e a grande cidade provincial adormecida e a vasta cidade industrial
atarefada, não há mais que uma diferença de grau, de nome ou de extensão.
Trata-se de espaços que, para o homem, diferem em qualidade e significado
(DARDEL, 2015, p.27).

Nesse sentido, o espaço construído estaria na urbanidade, compreendida como o centro de intervenção do homem na Terra, seja no desenvolvimento e exploração de recursos, à circulação e cruzamento de pessoas, lutas populares e experiências históricas. 
Vale ressaltar que Dardel não traz à tona revoluções/lutas campesinas ou mesmo a vivência do homem no campo, ou processos identitários pertencentes ao mundo campo/rural na tentativa de criar uma dialética rural-urbana, pelo contrário, ele é categórico em afirmar que o espaço construído é pertencente às populações urbanas. De acordo com ele:

As vezes arejado e opulento, às vezes miserável e repugnante, uma presença compacta, de onde pode nascer tanto essa polidez particular que chamamos de "urbanidade" quanto esses sobressaltos de revolta, esses motins que a história registra como reações próprias às populações urbanas (DARDEL, 2015, p.28).

A paisagem urbana é aqui tomada enquanto lugar de vivência, de uma realidade ao mesmo tempo concreta e imediata, pertencente ao mundo real - enquanto realidade -, e ao mesmo tempo enquanto espaço de vivência com o Outro. Esse Outro aqui não é aprofundado de sentido, mas constituído enquanto relação de socialização.

A cidade não é somente um panorama abarcado com um golpe de vista. A cidade, como realidade geográfica, é a rua. A rua como centro e quadro da vida cotidiana, onde o homem é passante, habitante, artesão; elemento constitutivo e permanente, às vezes quase inconsciente, na visão de mundo e no desamparo do homem; realidade concreta, imediata, que faz do citadino "um homem de rua", um homem diante dos outros, sob o olhar de outrem, "público" no sentido original da palavra (DARDEL, 2015, p.28).

Compreende-se então que em Dardel a complexidade do ser humano se reflete nas diversas formas com que se relaciona com o mundo (Terra). As percepções construídas em suas vivências vão além da compreensão racional a respeito dos fenômenos, comportando um estrato pré-intelectual nutrido especialmente da sensibilidade estética, da imaginação e da criação poética.

Podemos inferir ainda que a experiência de interação do ser humano com a natureza e os lugares habitados é um apelo à experiência e sensibilidade estética e vivencial. Nota-se que em seus espaços cotidianos estão claramente presentes a busca pelo belo (natural ou construído) e os traços da criação de sublimidades, repletas de significações que acabam por configurar os modos de viver e as construções culturais dos grupos que os compartilham. 


\section{Conclusões}

Segundo Heidegger (2007), somente representa-se o que é técnico, quando se satisfaz com a técnica, deste modo, se permanece sem liberdade, mesmo que se negue ou a valide cegamente, o ser-aí está entregue à técnica quando a considera como algo neutro.

Nesse sentido, ficaria a cargo da arte, do universo subjetivo, o despertar, e o retorno aos questionamentos do ser, sendo ela a razão que abre o consciente, e a partir dele que se questiona, portanto, vivencia-se o processo de angústia para chegar à essência. Contudo, quanto mais se reflete e questiona-se sobre a essência da técnica, mais carregada de enigmas será a essência da arte (HEIDEGGER, 2007). Assim quanto mais o ser-aí olhar para si próprio, quanto mais ele se questionar, mais próximo ele estará da consciência de ser a partir do que ele é, portanto, seria na essência que se produziria as bases firmes para se desenvolver a existência.

Em Dardel essa existência estaria na realidade geográfica, a realidade ver e habitar a Terra, de ser e experienciar com o outro e com a natureza. Dardel constrói assim a filosofia da realidade geográfica, do discurso geográfico, do ponto de vista geográfico, de como o geógrafo lê e vê o mundo, portanto, a geografia da descrição poética naturalista do trabalho de campo geográfico.

\section{Referências bibliográficas}

BACHELARD, Gaston. A água e os Sonhos. Rio de Janeiro, Livraria Martins Fontes Editora. 1989.

BACHELARD, Gaston. A psicanálise do fogo. Trad. Paulo Neves. São Paulo: Martins Fontes, 1994.

BACHELARD, Gaston. A Terra e os Devaneios da vontade. São Paulo, Livraria Martins Fontes Editora. 1991.

BACHELARD, Gaston. A Terra e os Devaneios do repouso. Trad. Paulo Neves da Silva. São Paulo, Martins Fontes. Ed; 1990.

BACHELARD, Gaston. $\mathrm{O}$ Ar e os Sonhos. Rio de Janeiro, Livraria Martins Fontes Editora, 1990.

BACHELARD, Gaston. O racionalismo aplicado. Tradução de Nathanael C. Caixeiro. Rio de Janeiro: Zahar Editores, 1977. 
BESSE, Jean-Marc. Ver a Terra: seis ensaios sobre a paisagem e a geografia. Trad. Vladimir Bartalini. - São Paulo: Perspectiva, 2014.

CIDADE, L. C. F. Visões de mundo, visões da natureza e a formação de paradigmas geográficos. Terra Livre, São Paulo, n.17, p. 99-118, 2001.

DARDEL, Eric. O Homem e a Terra: natureza da realidade geográfica. Trad. Werther Holzer. São Paulo: Perspectiva, 2015.

HEIDEGGER, Martin. Ontologia. Hermenêutica da facticidade. Trad. Renato Kirchner. Petrópolis: Vozes, 2013.

HEIDEGGER, Martin. A questão da técnica. Scientiæzudia, São Paulo, v.5, n.3, p. 375378, 2007.

JAPIASSÚ, Hilton. Para Ler Bachelard. Rio de Janeiro, F. Alves, 1976.

MERLEAU-PONTY, M. Fenomenologia da percepção. Tradução Carlos Alberto Ribeiro de Moura. São Paulo: Martins Fontes, 1999.

NEVES, M. R. C. 2020. A atitude fenomenológica e sua importância para a Geografia: desdobramentos atuais, diálogos metodológicos e concepções ontológica-hermenêutica da geograficidade das paisagens. Belo Horizonte, 213p. Tese de Doutorado em Geografia. Universidade Federal de Minas Gerais.

NEVES, M.R.C. 2015. O Mercado Municipal de Diamantina (MG): relações de identidade na ótica fenomenológica. Belo Horizonte, 133p. Dissertação de Mestrado em Geografia. Universidade Federal de Minas Gerais. 